\title{
Correlation between central corneal thickness, applanation tonometry, and direct intracameral IOP readings
}

\author{
Nicolas Feltgen, Dorothee Leifert, Jens Funk
}

\begin{abstract}
Background-Several authors reported incorrect high intraocular pressure (IOP) values in eyes with a thick cornea using applanation tonometry. This hypothesis was checked by comparing applanation tonometry with direct intracameral manometry.

Methods-73 patients, scheduled for intraocular surgery, were enrolled. Immediately before surgery, the following were registered: (i) central corneal thickness (CCT), (ii) applanatory IOP (Perkins/ Tonopen), and (iii) intracameral IOP.

Results-The difference between applanatory and intraocular measurements was completely independent of CCT $(y=-3.43+3.8 x$; where $y$ is the difference between applanatory and intracamerally measured IOP ( $\mathrm{mm} \mathrm{Hg}$ ) and $\mathrm{x}$ is CCT $\left.(\mathrm{mm}) ; r^{2}=0.002 ; \mathrm{p}=0.72\right)$.

Conclusions-There is no systematic error of applanation tonometry with increasing CCT. Therefore it is inadequate to recalculate IOP based on regression formula of applanatory IOP versus CCT. (Br f Ophthalmol 2001;85:85-87)
\end{abstract}

When Goldmann and Schmidt presented their applanation tonometer in 1957, they stressed certain possible sources of error. Central corneal thickness (CCT) was one of them. ${ }^{1{ }^{2}}$ Later on some groups reported thicker corneas in patients with higher intraocular pressure (IOP) compared with thinner corneas in patients with lower IOP. ${ }^{3-10}$

Varying corneal rigidity was claimed to be responsible for false applanatory IOP readings with different CCT. Some authors recommended a recalculation of the IOP depending on the CCT with a correction factor ranging from 1 to $6.8 \mathrm{~mm} \mathrm{Hg}$ per $0.1 \mathrm{~mm} \mathrm{CCT.}^{4-6810}$

The intention of this study was to reevaluate this assumption by correlating the CCT with applanation tonometry and intraocular IOP readings.

Dr med Nicolas Feltgen,

Universitäts-Augenklinik,

Killianstrasse 5, 79106

Freiburg, Germany

feltgen@aug.ukl.uni-freiburg.de

Accepted for publication 27 July 2000

Patients and methods

A total of 73 patients (73 eyes) were prospectively enrolled. All patients gave their consent before their inclusion in the study. They were scheduled for intraocular surgery for glaucoma $(n=31)$ or retinal diseases $(n=42)$.

The mean age was 40.7 years, ranging from 13 to 88 years. Patients with more than $1.5 \mathrm{D}$ astigmatism or corneal abnormalities were excluded.

After retrobulbar or general anaesthesia measurements were performed in the theatre with the patients supine. While one investigator (NF) measured CCT and applanatory IOP, a second investigator, the surgeon, performed intracameral IOP measurements. Four surgeons participated in this study.

An eyelid retractor was placed and the CCT was determined with an ultrasonic pachymeter (Pachette, DGH-Technology Inc). The IOP was measured first with the Perkins tonometer followed by the Tonopen (Mentor). The eyelid retractor was removed and the patient was prepared for surgery.

Every operation started by placing the eyelid retractor. Then the intracameral measurement was performed immediately. We used a special device developed by the University of Düsseldorf. ${ }^{11}$ It consists of an invasive blood pressure monitor as used in intensive care (Cardiocap II; Datatex Engstrom) connected to a specially designed transducer (Monitoring Kit; Abbott) and a steel cannula. This cannula was placed in the anterior chamber for about 10 seconds until the readings on the monitor were stable (Fig 1). Thereafter, the cannula was removed and surgical treatment begun. The agreement of methods was validated calculating the mean difference (md) and the standard deviation of the differences (SD) between applanatory and intracamerally IOP. $^{12}$

\section{Results}

The CCT values ranged from 0.448 to 0.713 $\mathrm{mm}$ (mean 0.58 (SD 0.054) $\mathrm{mm}$ ).

The applanatory IOP readings varied from 8 to $32 \mathrm{~mm} \mathrm{Hg}$ (mean 17.5 (6.5) $\mathrm{mm} \mathrm{Hg}$ ) using the Perkins tonometer, and from 7 to $38 \mathrm{~mm}$
$\mathrm{Hg}$ (mean 18.7 (7.2) $\mathrm{mm} \mathrm{Hg}$ ) using the Tonopen. 


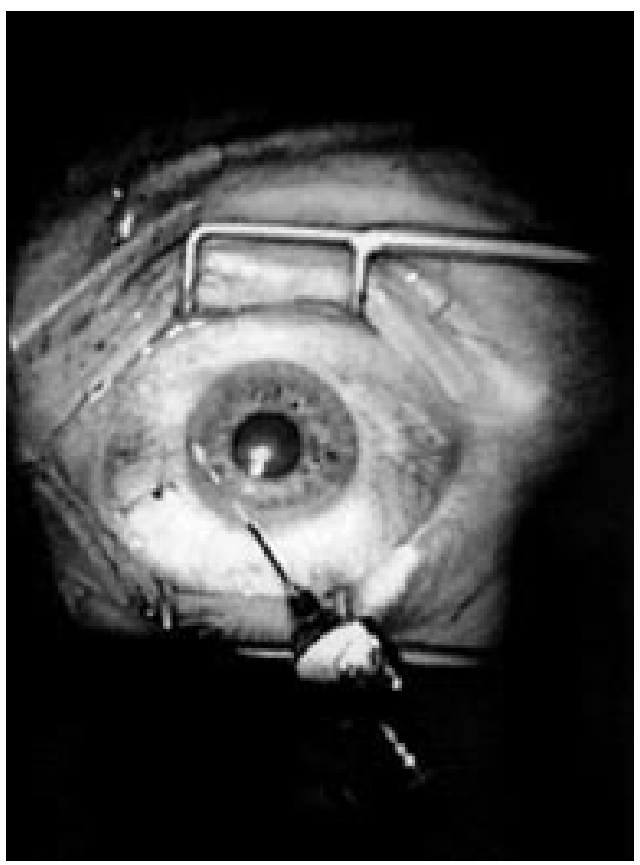

Figure 1 Cannula placed in the anterior chamber.

There was a strong correlation between these two methods $\left(r^{2}=0.866 ; \mathrm{p}<0.0001\right)$. The mean of the two methods was calculated and used as applanatory IOP (IOPappl) for further statistics.

Intraocular IOP readings varied from 8 to 37 $\mathrm{mm} \mathrm{Hg}$ (mean 19.5 (6.5) $\mathrm{mm} \mathrm{Hg}$ ). Comparing IOPappl and intracameral readings, the regression formula is $y=2.91+0.78 \mathrm{x}$ (where $\mathrm{y}$ is IOPappl $(\mathrm{mm} \mathrm{Hg})$ and $\mathrm{x}$ is the IOP measured by cannula $\left.(\mathrm{mm} \mathrm{Hg}) ; r^{2}=0.56 ; \mathrm{p}<0.0001\right)$. In four patients the difference varied by more than $10 \mathrm{~mm} \mathrm{Hg}$.

Calculating the methodical agreement between applanation and intracameral measurement, the mean difference was $1.2 \mathrm{~mm} \mathrm{Hg}$ and the standard deviation of the differences was $4.6 \mathrm{~mm} \mathrm{Hg}$. To determine the influence of the corneal thickness on applanation tonometry we compared CCT with the difference between applanatory and intraocular measurements.

There is nearly no increase of this difference with increasing CCT as depicted in Figure 2 $(y=-3.43+3.8 x$; where $y$ is the difference of

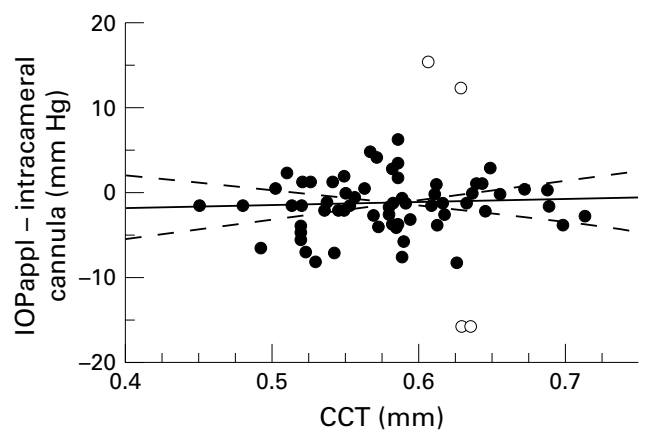

Figure 2 Difference between IOPappl and intracameral cannula correlated with CCT. Readings differing by more than $10 \mathrm{~mm} \mathrm{Hg}$ are marked as circles. $y=$ $-3.43+3.8^{\star} C C T, r^{2}=0.002 ; p=0.72, n=73$. applanatory minus intracamerally measured IOP $(\mathrm{mm} \mathrm{Hg})$ and $\mathrm{x}$ is CCT $(\mathrm{mm}) ; r^{2}=0.002$; $\mathrm{p}=0.72)$.

\section{Discussion}

We found a good correlation between (a) applanatory versus intracamerally measurement, and (b) Tonopen versus Perkins. This is in line with similar results recently described by Marx et al. ${ }^{11}$ To determine the methodical agreement, we calculated the mean difference and the standard deviation of the differences between IOPappl and intracameral IOP. ${ }^{12}$ Accordingly, $95 \%$ of these differences ranged within plus or minus $4.6 \mathrm{~mm} \mathrm{Hg}$ of the mean. This indicates a moderate agreement between the methods used. There is no doubt that applanation tonometry is the clinical gold standard; however, we believe intracamerally measured IOP values reflect the "true" IOP more accurately.

Goldmann was aware that corneal rigidity has to be considered if IOP is measured by applanation. Although he claimed CCT altered the measurement, he expected no clinically relevant misreadings. However, several authors described a positive correlation and recommended a recalculation of IOP depending on CCT. ${ }^{4-6-10}$

Intraocular readings are independent of CCT. If applanation tonometry gives artificially high values in patients with thick corneas and artificially low values in patients with thin corneas, intraocular and applanatory readings should divert as CCT rises.

In our study, the difference between intracameral and applanation tonometry did not increase with increasing CCT. Based on these findings it is concluded that applanatory readings are presumably not methodically influenced by CCT.

As the $95 \%$ confidence bands show (Fig 2), a minimal positive as well as a minimal negative correlation is unlikely. But it cannot be excluded completely. The statistical uncertainty, however, is of no relevance in clinical practice.

As can be seen from the same figure IOP values of thicker as well as of thinner corneas fluctuate widely above and below the regression line. Obviously, applanatory IOP readings can be too high as well as too low, independent of corneal thickness. Therefore, one cannot predict whether the "true" IOP value is higher or lower than a given applanatory IOP reading.

From this result we conclude that the use of any global recalculation formula is unsuitable to find the true IOP in clinical practice.

Furthermore, there is no need to combine the measurement of applanatory IOP and pachymetry. In cases of doubt an intracameral IOP measurement is recommended.

Proprietary interest: Nil.

1 Goldmann H, Schmidt T. Über Applanationstonometrie. Ophthalmologica 1957;134:221-42.

Ophthalmologica 1957;134:221-42.
Goldmann H, Schmidt T. Weiterer Beitrag zur Applanationstonometrie. Ophthalmologica 1961;141:441-56. 
3 Hansen F, Ehlers N. Elevated tonometer readings caused by a thick cornea. Acta Ophthalmol (Copenh) 1971;9. $775-8$.

4 Herndon LW, Choudhri SA, Cox T, et al. Central corneal thickness in normal, glaucomatous, and ocular hypertensive eyes [see comments]. Arch Ophthalmol 1997;115:113741. Comment in Arch Ophthalmol 1998;116:544-5, comment in Arch Ophthalmol 1998;116:701. Comment in Arch Ophthalmol 1998;116:1263.

5 Ehlers N, Bramsen T, Sperling S. Applanation tonometry and central corneal thickness. Acta Ophthalmol (Copenh) 1975;53:34-43.

6 Whitacre MM, Stein RA, Hassanein K. The effect of corneal thickness on applanation tonometry. $A m \quad \mathcal{F}$ Ophthalmol 1993;115:592-6.

7 Argus WA. Ocular hypertension and central corneal thickness. Ophthalmology 1995;102:1810-12.
8 Johnson M, Kass MA, Moses RA, et al. Increased corneal thickness simulating elevated intraocular pressure. Arch Ophthalmol 1978;96:664-5.

9 Copt RP, Thomas R, Mermoud A. Corneal thickness in ocular hypertension, primary open-angle glaucoma, and normal tension glaucoma. Arch Ophthalmol 1999;117:14-6. (Comment in Arch Ophthalmol 1999;117:104-5.)

10 Stodtmeister R. Applanation tonometry and correction according to corneal thickness. Acta Ophthalmol (Copenh) 1998;76:319-24.

11 Marx W, Madjlessi F, Reinhard T, et al. More than four years experience with electronic intraocular needle tonometer. Ophthalmologe 1999;96:498-502.

12 Bland JM, Altman DG. Statistical methods for assessing agreement between two methods of clinical measurement. Lancet 1986;1:307-10.

\section{Contributors please note:}

Communications from all countries except the UK and Republic of Ireland should be sent to Professor C Hoyt, Editor, British fournal of Ophthalmology, University of California, Department of Ophthalmology, 10 Kirkham Street, K 301, San Francisco, CA 94143-0730, USA (tel: 001415 502-6871; fax: 001415 514-1521).

Manuscripts from the UK and the Republic of Ireland should be sent to Professor Andrew Dick, UK Editor, British fournal of Ophthalmology, Division of Ophthalmology, University of Bristol, Lower Maudlin Street, Bristol BS1 2LX (tel: +44 (0) 0117 929-4496; fax: +44 (0) 117 929-4607). 